\title{
MUSAS DE ÉBANO: MARCHA A TRAVÉS DEL ATLÁNTICO
}

POR

\author{
Cristina Rodríguez Cabral
}

North Carolina Central University

\author{
En mi jaula \\ de ventanas y cristales, \\ encerrada en un mundo \\ de extraños, los días \\ en un otoño frío \\ donde no acude nadie. \\ Raquel Ilombé, "Soledad"
}

\author{
Convertiré esta muerte en fuego; \\ este árbol desgastado, \\ en ceniza y viento... \\ Liberaré mi alma herida \\ en pájaro. \\ Volaré sin cuerpo, \\ sin corazón, \\ sin miedo.
}

Edelma Zapata Pérez, "Poema 35"

Raquel Ilombé y Edelma Zapata: los sitios de la ausencia

Raquel Ilombé (Corisco, Guinea Ecuatorial; 1939-1992) y Edelma Zapata (La Paz, Colombia; 1954-2010) son dos poetas que difieren en sus propuestas líricas, pues éstas resultan de una estética propia y de la interacción de diferentes circunstancias: Ilombé, cuya vida se divide entre la memoria de Guinea Ecuatorial y su larga estancia en España; y Zapata, quien habita en su natal Colombia pero en una suerte de exilio social a causa de una enfermedad crónica. Sin embargo, el lirismo de ambas crea una atmósfera común al momento en que sus plumas se entregan a la evocación y representación de una problemática existencial caracterizada por un límite entre la pertenencia y el rechazo. Las voces poéticas de Ilombé y Zapata recrean, desde distintas perspectivas, sensaciones de encierro, aislamiento y soledad. Al tiempo que estas sensaciones señalan puntos de quiebre con el mundo que las rodea, también dan vida a un espacio poético, una matria, en donde las sendas voces poéticas confeccionan un esfera de alivio y confort espiritual. Esta matria creada en torno a recuerdos de Guinea, en Ilombé, y visiones oníricas de Frida Kahlo, en Zapata, surge, en parte, de la redefinición de los códigos patriarcales que circunscriben los conceptos de "patria" y "nación". Matria incorpora, según Sandra M. Gilbert, las nociones de madre ("the forgotten imposible 
dead mother") y matriz ("the originary womb or matrix, the mother-matter whose very memory, says Freud, is 'lost in a past so dim'...”) (195). ¿Cómo logra Ilombé delimitar y superar el sentimiento yuxtapuesto de la presencia y ausencia del allá y el aquí desde su exilio en la primera infancia? ¿Cómo la voz de Zapata poetiza y negocia la salida de las coordenadas existenciales en las que se sitúan el dolor físico y la alienación social? ¿Surge una propuesta estética común en el manejo poético de estas situaciones de entreespacio? Estas son las preguntas generales que guían este análisis. ${ }^{1}$

De diásporas africanas: voces de Colombia y de Guinea Ecuatorial a través del AtLÁNTICO

Así como millones de africanos fueron forzados a emigrar entre los siglos XVI-XIX al "nuevo continente" americano en condición de esclavos, como es el caso de los ancestros de Zapata; en el siglo xx la situación política de pos-independencia en Guinea, forzaría la marcha de artistas e intelectuales hacia el "viejo continente" europeo y otros países africanos, especialmente hacia sus vecinos Gabón y Camerún (Cusack 226-29).

Las experiencias de la diáspora, forzadas por distintos fenómenos políticos y sociales siembran en las dos poetas sensaciones de angustia y dolor. La manera en que Ilombé supera dichos sentimientos es elaborando un escape virtual hacia Guinea, la desborda los límites de un estado político para transformarse en un estado espiritual con características femeninas. Es a través de la construcción de un espacio maternal específico, una matria, que Ilombé articula la realidad de su ser/patria herida y la fantasía "of her own female/poetic revitalization..." (Gilbert 195).

Raquel Ilombé (nacida Raquel del Pozo Epita), hija de madre africana y padre español, es separada de su madre a la edad de dos años y es trasladada a España con su padre, con quien vivirá entre las ciudades de Burgos y Madrid, y junto a quien la poeta reportara a M'bare N'gom en una entrevista haber tenido "una infancia fenomenal y una juventud muy buena" (54). Creyendo a su madre muerta, Ilombé crece en España junto a la familia paterna. Aunque España es el lugar donde Ilombé se cría y constituye una familia, es en Guinea donde aflora la continuidad de una historia desgajada. Es a la edad de veinticuatro años, aproximadamente en el año de 1963, y tras la muerte de su padre, que Ilombé regresa con su esposo de visita a Guinea Ecuatorial y descubre que su madre aún estaba viva. Es después de este reencuentro que, en 1978 Ilombé publica su poemario Ceiba, mismo que será la primera obra lírica publicada por un autor guineano.

1 En este análisis, uso el término "exilio" con varios matices; lo refiero en cuanto a su definición de estado prolongado de alejamiento del país de origen sin importar las causas que lo determinan. Por su parte, empleo la imagen de "musas de ébano" para referir al mismo tiempo al exilio de Ilombé y al insilio que supone la enfermedad crónica de Zapata.

Revista Iberoamericana, Vol. LXXX, Núms. 248-249, Julio-Diciembre 2014, 835-847 ISSN 0034-9631 (Impreso)

ISSN 2154-4794 (Electrónico) 
Este sorprendente reencuentro con la madre reinyecta un nuevo significado a los poemas de Ceiba. Sirvan de ilustración las líneas del poema "Soledad" incluidas en el epígrafe que da inicio a estas páginas. La voz poética de "Soledad” distingue la sensación de encierro y aislamiento en un país donde ella se sentía extraña, amurallada en una lejanía inexplicable y que quizás, pudiera emparejarse como el hecho biográfico de la autora y calificarse de un extrañamiento causado por el silenciamiento de la existencia de su madre, y, por tanto, de sus conexiones vivas con el país que le vio nacer. El desplazamiento geográfico de Ilombé se convierte en un exilio no sólo de lugar de origen materno, sino que también la aliena en lo íntimo. De esta forma, el suyo es también un inxilio, causado por el ocultamiento de una verdad que resulta en su aislamiento de la esfera familiar y que marca su percepción de aquellos con quienes convive, tal como señala el poema.

Al otro lado del mundo, otra poeta, Edelma Zapata, traza en su obra otra forma de alienación en donde confluyen el relativo exilio social que condiciona la vida de los afrocolombianos, y, el aislamiento resultante del padecimiento de una enfermedad crónica. En Zapata, por tanto, también convergen la dinámica exilio/inxilio. Los sentimientos de angustia y dolor son el resultado de una enfermedad, mismos que son exorcizados por la voz poética a través de la construcción de una matria, que será un espacio mental de refugio inspirado en torno a la presencia mística de Frida Khalo.

Edelma Zapata Pérez nacida en La Paz en 1954 de ascendencia afro-indo-europea es hija del prominente escritor desaparecido Manuel Zapata Olivella, a quien acompañó en sus investigaciones sobre oralidad y cultura popular colombiana. Muy activa en el forum cultural colombiano, Edelma Zapata ha dirigido por diez años los espacios radiales Identidad Colombiana y Afro-Colombia. En 1999 publica Ritual con mi sombra y recientemente finalizó los poemarios La otra cara de la luna (del cual se prepara la traducción y publicación al inglés) y Rumores de la melancolía (recogidos algunos de ellos en la Publication of the Afro-Latin/American Research Association, 114-18).

Desde la edad de quince años Zapata padece de artritis reumatoidea, enfermedad crónica progresiva que la sumerge en prolongados estados de dolor y postración. Si bien la poeta ha creado gran parte de su obra en situaciones de dolor, como se evidencia en la voz poética del epígrafe de Poema 35, el sujeto poético no se auto-victimiza. La mayor parte de su producción poética revela una actitud positiva orientada hacia la superación del género humano, así como un gran interés en los problemas sociales que aquejan a la humanidad y al medio ambiente en nuestros días.

El constructo matria como artificio teórico permite abordar, investigar y comparar la propuesta estética que ambas autoras, Ilombé y Zapata, construyen en su espacio poético, uno de total pertenencia en el cual pueden habitar completamente al unísono como seres humanos, como víctimas del dolor corporal y existencial, y como fantasmas creados por sus voces poéticas.

Revista Iberoamericana, Vol. LXXX, Núms. 248-249, Julio-Diciembre 2014, 835-847 ISSN 0034-9631 (Impreso) ISSN 2154-4794 (Electrónico) 


\section{RAQUEL ILOMBÉ: EN BÚSQUEDA DE LA MATRIA GUINEOECUATORIANA}

Existe en el corpus literario de Guinea Ecuatorial una consolidada tradición de la poética del exilio; el exilio en España, sobre todo. Hay una serie de factores que explican el hecho de que España haya sido el puerto de arribo mayormente elegido por los exiliados guineanos. Entre otros, se destacan las relaciones culturales y de intercambio establecidas durante el periodo colonial, el uso de una lengua común y las conflictivas relaciones políticas entre los gobiernos guineano y español tras la independencia. A pesar de las iniciales condiciones favorables de España hacia los inmigrantes de la antigua colonia, la "Madre Patria" no siempre abrió sus brazos para recibir a los hijos de su ex colonia africana y, a través de los años, se alternaron periodos de mayor y menor apertura hacia la presencia de inmigrantes guineanos. En 1999, durante las “Jornadas sobre Guinea Ecuatorial" realizadas en Madrid, el escritor y periodista guineoecuatoriano Donato Ndongo-Bidyogo destaca la actitud asumida por el gobierno español durante el lapso de tiempo transcurrido entre la independencia de Guinea (1968) y la presidencia de Adolfo Suárez (1976) donde "los guineanos fuimos borrados de la conciencia de España" (1). En esos años, el gobierno de Franco declaró "materia reservada" todo lo concerniente a Guinea, lo que significó, entre otras cosas, que a los guineanos que huían de la represión del gobierno dictatorial de Francisco Macías (1969-1979) se les prohibiría residir legalmente en territorio español. Ndongo-Bidyogo señala que esto condujo a que varios guineoecuatorianos, como el poeta Joaquín Mbomio, ${ }^{2}$ se exiliaran en Suiza. Como lo destacó Marvin Lewis, para la lírica de Guinea Ecuatorial: "Exile is the dominant theme of poets living abroad..." (15).

Sin embargo, esta vertiente de la poética del exilio por parte de la mayoría de los escritores guineanos que salen del país a causa de las presiones de los regímenes dictatoriales poscoloniales en Guinea Ecuatorial es esencialmente diferente a la propuesta de Ilombé. Una de las razones de tal diferencia se debe a que, para Ilombé, dadas sus circunstancias personales y familiares, Guinea no representa la patria prohibida a la cual no puede regresar. En su lírica, Guinea es lugar de nacimiento, pero también, donde reside la verdad raptada de su historia maternal. Guinea es la memoria enterrada del espacio en donde se generaron sus primeras experiencias de vida. Desde este ángulo, Guinea simboliza la madre-patria, la matria, el útero epistemológico en el cual germina la lírica poética del exilio en forma independiente de la coyuntura política del país.

\footnotetext{
El exilio provoca una vasta gama de sentimientos compartidos entre los autores; la poética de Mbomio es un ejemplo representativo de los temas abordados durante el período en cuestión. Entre dichos temas destacan la esperanza de regreso a la patria junto a una romántica evocación del continente africano como lo exponen los versos de "El Retorno": "Volveré a las tierras africanas, / regresaré al paraíso verde / donde nací y crecí / en el seno de la naturaleza. / Volveré a esa África / donde la tierra vestida / siempre esta de gala;" (1-7). Afro-Hispanic Review, special issue on Ecuatorial Guinea (2000).
}

Revista Iberoamericana, Vol. LXXX, Núms. 248-249, Julio-Diciembre 2014, 835-847 ISSN 0034-9631 (Impreso) ISSN 2154-4794 (Electrónico) 
Así, su poética manifiesta conflictos de identidad propias de la violentación del desplazamiento de un espacio geopolítico a otro. En "Quien soy", la voz poética adquiere un tono de confesión, de culpa, por no sentir pertenencia a su entorno español: "El cielo hable por mi / que yo no sé explicarme...". Sin embargo, de este sentimiento también afloran en la voz poética estrategias de escape. En los versos de "Soledad" que siguen a los del epígrafe, se lee:

\author{
Cuando sola en mi casa \\ me encuentro por las noches \\ que sólo oigo mis voces, \\ envuelta en una manta \\ voy bajando escalones \\ por si encuentro escondida \\ aquellas ilusiones \\ que hoy tengo perdidas. \\ En esas pocas horas \\ que puedo estar dormida \\ vivo en sueños \\ escenas tan queridas \\ que el sol en mis mares \\ alumbra más deprisa. \\ Una rosa entreabierta, \\ esbelta, sin espinas, \\ aquella que en mis manos \\ en tiempos ya lejanos \\ se abría cada día. \\ Cuando despierto, \\ no hay rosas, \\ sólo sangre y espinas.
}

La "jaula" de los versos del epígrafe es tan solo la punta del iceberg de un encierro mayor "en un mundo de extraños". La posibilidad de escape surge a través de la imagen de una escalera que facilita un descenso, un ansiado regreso por parte de la voz poética hacia su pasado, su niñez, hacia un imaginario coartado. Si bien no se menciona a Guinea en el poema, se alude su presencia a través del sol y los mares de la tercera estrofa. Pese a la anteriormente mencionada declaración de la autora de haber tenido una infancia y juventud muy buenas en España, Ndongo Bidyogo señala que la poeta "siempre vivió en la añoranza de los húmedos calores de su infancia, de los que fue arrancada para ser transplantada a la gélida sequedad de la meseta castellana" ("Literatura moderna" 130).

Revista Iberoamericana, Vol. LXXX, Núms. 248-249, Julio-Diciembre 2014, 835-847 ISSN 0034-9631 (Impreso) 
La imagen onírica de la escalera del poema "Soledad" sugiere un mecanismo de evasión al encierro, el frío, la soledad y al presente; la escalera se torna en vía de acceso hacia escenarios revestidos de soles y mares que evocan un pasado lejano y borroso en Guinea. Pero la fuga por la escalera de su sueño es temporal y el poema concluye con el abandono abrupto del espacio onírico; de regreso a la realidad reaparece el dolor, simbolizado ante la ausencia de rosas y la presencia de sangre y espinas. Tomando en cuenta el contexto histórico de 1977 (año en que el poema fue escrito) "sangre y espinas" pueden hacer referencia a la dictadura de Macías, la cual azotaba los campos y ciudades en tal periodo. En fin, el poema "Soledad", de tono casi surrealista, alude a la madre-patria en un acercamiento a lo afectivo, lo querido/perdido, al paralelismo entre la madre ausente y la Guinea ensangrentada en tiempos de Macías. La suerte postindependentista de Guinea es, pues, silenciada, como la existencia de la madre. De acuerdo a Edward Friedman, Teresa Valdivieso y Carmelo Virgilio "la poesía nació de la exigencia innata en el ser humano de preservar su pasado" (147). En "Soledad" la preservación del pasado es también aserción de la existencia de la realidad africana. Entonces, la afirmación de la memoria y la añoranza del lugar de origen se presentan como una clara cuestión de sobrevivencia para la voz poética, siendo esta la forma con la cual supera la sensación de no pertenencia.

\section{Edelma Zapata PÉReZ: LA Matria PERSONIFICADA EN LA MUSA ENFERMA}

Al otro lado del Atlántico, en el continente americano, las hijas de la diáspora africana experimentan también sensaciones similares a las referidas anteriormente. Las manifestaciones de otredad manifiestas en "Soledad" de Ilombé fueron motivadas por el alejamiento de la patria, mientras que en Zapata será debido a la presencia de una enfermedad. Ella, quien reside en su natal Colombia, pasa la mayor parte del tiempo alternando entre dolorosas cirugías y estados de postración parcial o total en su departamento en la ciudad de Bogotá. En este contexto, la enfermedad opera como frontera entre la vida y la muerte aislando al individuo, en forma temporal o permanente, del medio ambiente. La enfermedad actúa como detonador primario de dolencias físicas y existenciales, e, igual que en el caso de Ilombé, la voz poética de Zapata desarrollará estrategias de escape hacia un estado más satisfactorio desde donde pueda enfrentar/ resistir el dolor y sus repercusiones. En forma contraria a la estética de Ilombé, las noches para la voz poética de Zapata son el intersticio hacia estados de angustia y desesperación. Elaine Scarry en la introducción a The Body in pain: The Making and Unmaking of the World señala que "... for the person in pain, so incontestably and unnegotiably present is it that 'having pain' may come to be thought of as the most vibrant example of what it is to "have certainty'," (4) Si bien para el paciente la sensación de dolor se iguala a la de certeza, para el médico la misma continúa siendo una gran incógnita: "Physical pain

Revista Iberoamericana, Vol. LXXX, Núms. 248-249, Julio-Diciembre 2014, 835-847 
does not simply resist language but actively destroys it, bringing about an immediate reversion to a state anterior to language, to the sounds and cries a human being makes before language is learned." (4) Zapata se enfrenta, entonces, ante el reto de expresar un ámbito cognitivo/emocional que pone al lenguaje al límite: deberá crear una red de símbolos e imágenes que logren trasmitirle al lector la intensidad y el alcance de su dolor físico.

La experiencia del dolor físico es bien conocida para la poeta quien, desde su juventud, padece de artritis reumatoidea; por lo tanto, para Zapata la superación del dolor ha sido, a la vez, un desafío y una forma de vida. El dolor físico y la creación poética se convierten en una presencia tan poderosa en la vida de esta poeta que la han llevado a declarar en su "Esbozo autobiográfico": "Una musa y una cruz han sido mis compañeras perseverantes: la poesía y la enfermedad” (209). Pese a ser sometida repetidamente a intervenciones quirúrgicas de miembros y columna vertebral, la ciencia no ha logrado controlar el avance de su enfermedad cuya sintomatología se intensifica con el transcurrir del tiempo. Así describe Zapata su entorno: “... médicos, chamanes y amigos, las cirugías, y posteriormente la recuperación en medio del dolor, si puede llamarse recuperación a esta agonía diaria de un lento morir" (208), en el mismo ensayo. Sumadas a las preguntas existenciales sobre identidad afrocolombiana en una sociedad nacional discriminatoria, ${ }^{3}$ está pues lo concerniente a su pertenencia a una sociedad en la que, a raíz de sus limitaciones físicas no puede más que participar tangencialmente.

A pesar de estas restricciones, Zapata es una mujer activa, bien informada, con una mente dinámica y preocupada por los sucesos que ocurren en Colombia y en el resto del mundo; al igual que su padre, su obra poética y ensayística expone siempre una nota de interés social. Zapata posee una fuerza interior inquebrantable que se refleja en una creación poética profunda, reflexiva y esperanzadora, "una rosa que se abre a la vida", rescatando la imagen de alivio creada por Ilombé en "Soledad". No obstante, esporádicamente asoman nubes grises en su horizonte poético y surgen versos que son gritos de angustia como los contenidos en el epígrafe o en "Frida", ambos textos de la colección La otra cara de la luna.

FRIDA
Pincelada de sangre en la nieve.
Los ríos de la vida siempre regresan
Secreto de vida, paloma, secreto de muerte.
He leído muchas veces
en noches pálidas de luna, el libro de tus días:

4 Para más información leer "The Consciousness-Raising of an Afro-Indo-Mulatto Woman Writer in Colombia's Multiethnic Society" artículo de Edelma Zapata Pérez traducido por Laurence E. Prescott en Daughters of the Diaspora (360-69).

Revista Iberoamericana, Vol. LXXX, Núms. 248-249, Julio-Diciembre 2014, 835-847 ISSN 0034-9631 (Impreso)

ISSN 2154-4794 (Electrónico) 
tu mágico viaje, tus momentos ciegos, tu útero vacío. Cuenta la historia, la pena ya borrada.

Tu coja pata que sostuvo el mundo, tu parto de luces, momentos de tu vida que trenzo en la oscuridad, en el sabor amargo y húmedo de cárcel.

Arenas movedizas, tus noches y las mías. Todas ellas de sed y de locura. Los últimos escarceos me dejan rota el cuerpo fragmentado, la mente huidiza.

Asunto del montón:

"un corazón que late calladamente la pena ruidosamente el dolor", se abre a la vida. XOCOLAT

Mi noche espera, mi noche tiene nombre FRIDA.

¡Qué vainas tiene la vida!

Cuando la muerte te alcanzaba, yo nacía al claro día. Horror sagrado.

Para mí, la lanza destinada.

Hoy te daré mi canto y la alegría, no hablaremos de tu noche ni la mía.

Bordaremos un vestido en honor a Coatlicue:

Le pondrás clavos de tu corazón de luna, yo derramaré al viento una lluvia de plumas. Miraremos volar su falda en los jardines.

Frágil hija de corazón fuerte, tú que alguna vez dijiste:

"todo me duele, todo me penetra, el alba está siempre demasiado lejos".

Déjame mirar tu espejo, en ese otro espejo que es mi vida.

Déjame encender las cadenas del cuerpo.

Préstame tus dientes para roer la sal de la carne.

"Soy su presa y él mi destino, presa rebelde, pero presa sin duda".

Aguda amiga mía, de espinas, de hierro forjado en mi corazón clavada, óyeme decir contigo: 
"Pies para que los quiero si tengo alas para volar, espero alegre la salida y espero no volver jamás".

"Frida" se transforma conceptualmente en la musa protectora de la poética de Zapata, quien elabora imágenes ilustrativas de una identificación espiritual establecida con la pintora mejicana. "Los ríos de la vida siempre regresan", es una imagen alusiva al continuo retorno en el ciclo de la vida y la muerte ya utilizada por el autor pre-socrático Heráclito de Éfeso (535-475 AC). Esta idea se retoma en "Frida" sugiriéndose una suerte de coincidencia kármica entre la pintora Frida y la voz poética: "Cuando la muerte te alcanzaba, / yo nacía al claro día. Horror sagrado", refiriendo a una coincidencia de fechas: Zapata y Kahlo nacen un 6 de julio (1954 y 1907, respectivamente) mientras que Kahlo muere un 13 de julio en el mismo año de nacimiento de Zapata. En su "Esbozo autobiográfico" Zapata refiere a esta coincidencia que acompaña a la muerte de la pintora y al nacimiento de la poeta: "Frida, diosa de la muerte y de la vida, encadenada a mí en el tiempo, mueres un día de julio del cincuenta y cuatro, año de mi nacimiento" (203). La carga simbólica del primer terceto evoca la relación dinámica entre la vida y la muerte desde una perspectiva holística, como parte de un todo regido por leyes cósmicas. El espíritu de lucha y resistencia que caracterizó a Kahlo - “frágil hija de corazón fuerte"- es lo que rescata e impulsa a la voz poética; por ello, acude a la lectura de sus memorias como otras personas acuden a la de textos religiosos.

El dolor físico no solo conduce al aislamiento y la locura sino que también desprende un potencial energético. Me refiero a la energía surgida de la resistencia diaria, de ganarle una nueva batalla a cada noche de locura, de crear a pesar de / y a partir de las limitaciones del cuerpo. He aquí la razón de por qué la voz poética ofrecerá su canto y alegría a Frida, invitándola a olvidarse de sus noches y a dedicarse juntas a la labor de bordar un vestido "en honor a Coatlicue", madre diosa de la tierra en el panteón azteca, celebrando de esta forma las raíces indígenas mexicanas que la pintora gustaba exaltar en su pintura y vestimenta diaria. La mención de Xocolat, hace referencia a la diosa de la fertilidad en los panteones culturales mayas y aztecas. La voz poética mentaliza en forma surrealista una suerte de altar, construye un refugio en torno a la invocación espiritual de Frida y las diosas indígenas en el cual recupera energía para sobrellevar el desafío físico de sus noches con dolor.

En términos figurados y en forma circular, el poema ofrece varios cambios de tono donde el pesimismo inicial de la voz se convierte en júbilo y celebración, para luego tornarse en súplica "préstame tus dientes para roer la sal de la carne;" súplica que será la antesala del retorno al desaliento. El devenir de los ríos de la vida, del dolor temporal, se retoma para que el poema complete su estructura dramática culminando con un mensaje trágico, donde la muerte aparece como única salida, único escape permanente al encarcelamiento del cuerpo y de la mente. Ante esta evidencia la voz poética vuelve a refugiarse en la imagen de Frida, citando los últimos versos anotados por Kahlo poco

Revista Iberoamericana, Vol. LXXX, Núms. 248-249, Julio-Diciembre 2014, 835-847 ISSN 0034-9631 (Impreso)

ISSN 2154-4794 (Electrónico) 
antes de morir. La inclusión de elementos fríos, ásperos, capaces de infligir dolor cuya presencia, real y metafórica, en las vidas de Khalo y Zapata se convierte en el nexo material que valida la utópica amistad consagrada a través del dolor y del tiempo: "Aguda amiga mía, de espinas, de hierro forjado". El poema concluye en tono trágico donde la voz se apropia nuevamente de los últimos versos de Kahlo y junto a ella comparte su anhelo de una pronta y ultima liberación: "espero alegre la salida y espero no volver jamás".

\title{
CREAR ES RESISTIR
}

La asociación entre dolor físico y muerte que aparece en el imaginario de la voz poética de Zapata es consecuencia inevitable ante la constatación del avance de la enfermedad. El alivio temporal que brinda la evocación de Kahlo y las diosas aztecas y mayas Coatlicue y Xocolat es tan solo un retiro espiritual temporal que cede ante la tenacidad de la sintomatología. En forma similar sucedía en Ilombé cuando despertaba del sueño y se imponía la realidad del encarcelamiento. Pero en los recursos estilísticos de Zapata no hay visiones oníricas que permitan exhumar los demonios del dolor sino puro esfuerzo mental voluntario dirigido hacia un terreno surrealista dominado por la imagen de Frida Kahlo. Es en estas circunstancias extremas, tras haber agotado todos los medios disponibles, que la muerte es visualizada, como lo expresa Emily Dickinson, "Pain has but one Acquaintance / and that is Death" (Young y Baar 30). La explicación de cómo la voz poética logra superar ese inevitable deseo de muerte surge, por un lado, ante la permanencia del más básico instinto de vida; y por otro, tiene que ver con el desarrollo intelectual de la voz poética. Gilles Deleuze aborda la relación inversa existente entre salud e intelecto destacando que un estado débil de salud puede favorecer el desarrollo del intelecto:

\begin{abstract}
The question, says Deleuze, is whether the illness made something easier, not necessarily more successful though, specifically an enterprise of thought, and Deleuze thinks that a very weakened state of illness favors this. It's not that one is tuned in to one's own life, but for him, it did seem like he was tuned into life. Tuning into life is something other than thinking about one's own health. He repeats that he thinks a fragile state of health favors this kind of tuning-in. When he was speaking earlier about authors like Lawrence or Spinoza, to some extent they saw something so enormous, so overwhelming that it was too much for them. It really means, Deleuze says, that one cannot think if one isn't already in a domain that exceeds one's strength to some extent that makes one fragile. (Parnet) ${ }^{4}$
\end{abstract}

4 Transcripción traducida de "El Abecedario de Gilles Deleuze", entrevista realizada por Claire Parnet en 1996 correspondiente a la sección M as in Malady.

Revista Iberoamericana, Vol. LXXX, Núms. 248-249, Julio-Diciembre 2014, 835-847 ISSN 0034-9631 (Impreso) ISSN 2154-4794 (Electrónico) 
Mark Young y Karen Baar afirman en Women and Pain que "[Pain] involves a complex interaction between the mind and the body" (30). Sin embargo esta interacción no se restringe al dolor de la enfermedad, sino también a aquel del exilio social que supone la limitación física, en el caso de Zapata; y la diferencia étnica, el desplazamiento geográfico y la alienación de la propia historia maternal, en el caso de Ilombé. Es en este entramado que en los poemas de Zapata e Ilombé despuntan iconografías que agencian a las voces poéticas de una estrategia para intentar aliviar su situación, para escapar de su realidad de vacío/dolor/ aislamiento. La imagen de Frida cumple una función similar a la desempeñada por la escalera presentada en el poema referido de Ilombé. Por su parte, la selección del término "cárcel" por Zapata es paralela al de la representación de la "jaula" de Ilombé: la sensación de encarcelamiento y la elaboración de una poética de fuga se hallan presentes en ambas autoras, quienes por distintos aspectos del dolor (espiritual el de Ilombé, físico el de Zapata), transformaron sus respectivos encierros en liberaciones poéticas. En cuanto a la estética de los poemas, en ambos se presenta una dicotomía entre el día y la noche sugiriéndose que la lucha establecida por la voz poética es diaria y continua. Si bien la noche es fuente de vida en Ilombé, lo será de muerte en Zapata. Ambas autoras se valen de un objeto concreto para negociar el pasaje de un mundo real hacia otro virtual; "la escalera" en Ilombe es comparable "al libro de notas" en Zapata. Son los sueños quienes brindan una estadía placentera en Ilombé, mientras que Zapata se vale de un esfuerzo mental voluntario para lograrlo. Las imágenes oníricas de Ilombé resultan comparables a las surrealistas elaboradas por Zapata en cuanto a que ambas pertenecen al mundo tácito, aquel en el cual las protagonistas concretan su imaginario de no exclusión y pertenencia. Las estrategias literarias desarrolladas por ambas autoras permiten establecer un paralelismo entre sus obras a partir de la adopción del concepto de matria, el cual es representado por los fantasmas de la madre/tierra/ matriz/útero en Ilombé, y por el fantasma de Frida Khalo en Zapata.

En Ilombé, el alejamiento de la patria no significa aislamiento literario así como en Zapata, la enfermedad no significará exilio lírico. Al contrario, ambas hijas de África exorcizan las duras experiencias de vida pariendo versos, convierten sus dramas personales en musa poética. Ambas rescatan el lirismo de las situaciones límites que les ha tocado vivir creando una poesía libre y saludable que no evade el dolor ni la soledad, sino que los enfrentan en forma genuina. Las musas de ébano no refieren a estados de éxtasis en inspiración abstracta que llegan del exterior y embriagan al poeta; sino que refieren a la plena conciencia de estar viviendo una situación traumática, desbordante e íntima, y darse la libertad de convertirla en materia prima de la creación literaria. El exilio y la enfermedad aíslan a las poetas de su medio generándoles sensaciones de encierro y vacío; sin embargo, sus voces logran liberarlas abriendo su pequeño e intenso mundo hacia el exterior. De esta forma, la esfera privada se conecta, a través de la creación poética, con la esfera pública; siendo ésta la base de una propuesta estética y de vida.

Revista Iberoamericana, Vol. LXXX, Núms. 248-249, Julio-Diciembre 2014, 835-847 ISSN 0034-9631 (Impreso)

ISSN 2154-4794 (Electrónico) 
Las diferentes circunstancias diaspóricas de las autoras conducen a la elaboración de textos sugerentes de temas que de otra forma, permanecerían silenciados en las obras. En Ilombé, son los temas de la añoranza de un lugar mejor y de la no-pertenencia al medio -España- que la rodea. En Zapata, son la añoranza de un cuerpo que le permita integrarse plenamente a la sociedad; así como, la cultura de la enfermedad y la exclusión social que ésta impone. La resistencia de las voces de Ilombé y Zapata se concreta en cuanto acción liberadora, en su capacidad de crear un texto poético a partir de una circunstancia que las margina. En este proceso se revierten los códigos de marginación establecidos dando como resultado otra situación donde las protagonistas/poetas pasan de un estado de no pertenencia a otro de pertenencia. En ambas autoras, las estrategias de resistencia incluyen la no victimización de sus voces poéticas - quienes se convierten en heroínas tras el análisis-, planteando a la vez los matices trágicos de la situación personal que enfrentan.

"... to create is to resist," it's effective, positive; the world would not be what it is if not for art, says Deleuze, people could not hold on any more" (Parnet). ${ }^{5}$

\section{OBRAS CITADAS}

Afro-Hispanic Review 19/1 (2000). Special Issue devoted to Equatorial Guinea.

Arizona Journal of Hispanic Cultural Studies 8 (2004), special section: "Equatorial Guinea and Spanish Letters.”

Ashcroft, Bill, Gareth Griffith, and Helen Tiffin. Post-Colonial Studies: Key Concepts. New York: Methuen, 2000.

Ávila Laurel, Juan Tomas. Poemas. Malabo: Centro Cultural Hispano-Guineano, 1994. Historia íntima de la humanidad. Malabo: Ediciones Pangola, 1999.

Cusack, Igor. "Hispanic and Bantu Inheritance, Trauma, Dispersal and Return: Some Contributions to a Sense of National Identity in Equatorial Guinea." Nations and Nationalism 5/2 (1999): 207-36.

DeCosta-Willis, Miriam. Daughters of the Diaspora. Jamaica: Ian Randle Publishers, 2003.

Evita, Leoncio. Cuando los combes luchaban: novela de costumbres de la Guinea Ecuatorial. Madrid: Consejo Superior de Investigaciones Científicas, 1953.

Gilbert, Sandra M. "From Patria to Matria: Elizabeth Barrett Browning's Risorgimento."

PMLA (Publication of the Modern Language Association) 99/2 (1984): 194-211

Ilombe, Raquel. Ceiba. Madrid: Editorial Madrid, 1987.

Olo’ Mibuy, Anacleto. “Gritos de libertad y esperanza”. África 2000 IV (1987): 14-15.

5 Declaración de Gilles Deleuze en $R$ as in Resistance. Transcripción traducida de "El Abecedario de Gilles Deleuze", entrevista realizada por Claire Parnet en 1996.

Revista Iberoamericana, Vol. LXXX, Núms. 248-249, Julio-Diciembre 2014, 835-847 ISSN 0034-9631 (Impreso)

ISSN 2154-4794 (Electrónico) 
Parnet, Claire. "M as in Malady/Illness." El abecedario de Gilles Deleuze. Entrevista dirigida por by Pierre-André Boutang (1996). <http://www.langlab.wayne.edu/ cstivale/d-g/abc1.html>. 18 junio 2014.

Mbomio Bacheng, Joaquín. “Originales.” África 2000 IV, (1989): 34-35.

Nang, Mbol. "La estética de la poesía de don Ciriaco Bokesa". Cuadernos para la Investigación de la Literatura Hispánica 29 (2004): 321-39.

Ndongo Bidyogo, Donato, and M'bare N'gom, eds. Literatura de Guinea Ecuatorial (Antología). Madrid: SIAL, 2002.

"Literatura moderna hispanófona en Guinea Ecuatorial". I Jornadas de Estudios Africanos. Marta Sofía López, ed. León: Universidad de León, 2001. 125-35.

"La solución no depende de los guineanos". Opinión $<\mathrm{http}$ ://www.angelfire.com/ sk2/guineaecuatorial/ndongo.html>.

Nerin, Gustau. "El aislamiento, una amenaza constante. Entrevista a Donato Ndongo". Quimera 113 (1992): 51-55.

Ngom Faye, Mbare. Diálogos con Guinea: panorama de la literatura guineoecuatoriana de expresión castellana a través de sus protagonistas. Madrid: Edita Labrys, 54 S.L., 1996.

Scarry, Elaine. The Body in Pain: The Making and Unmaking of the World. New York: Oxford UP, 1985.

Young, Mark, and Karen Baar. Women and Pain. New York, 2002.

Zapata Pérez, Edelma. Ritual con mi sombra. Bogotá: El Astillero Ed., 1999. La otra cara de la luna. (Inédito). 2009.

Rumores de la melancolía. (Inédito). 2009.

"Espozo autobiográfico". Afro Hispanic-Review 28/1 (Spring 2009): 203-13. 
